\title{
PROGNOSIS OF SENILE \\ CATARACT EXTRACTION \\ WITH INCREASING AGE
}

\author{
BY \\ *IDU, F. K. and AJAYI, O. B. \\ DEPARTMENT OF OPTOMETRY, UNIVERSITY OF BENIN \\ BENIN CITY, EDO STATE, NIGERIA \\ Email: ajayiob@yahoo.com \\ *Corresponding author
}

\begin{abstract}
In order to determine the prognosis of senile cataract extraction with increasing age, a case series of 240 patients without ocular or systemic comorbidity aged 51 to 80 years who underwent intracapsular cataract extraction (ICCE), and extracapsular cataract extraction (ECCE), between January 1991 and Decembers 2000 was studied. The results revealed a significant difference in the visual acuity outcome between the different age groups $(\mathrm{P}<0.05)$. There was a strong negative correlation between age and the final visual acuity after cataract extraction $\mathrm{r}=-0.91(\mathrm{P}<0.012)$ showing a decrease in visual acuity with increasing age. Age range of 61-65 had the best visual acuity outcome (6/9) after ICCE, while age range 51-55 had the best visual acuity outcome (6/7.5) after ECCE. In both ICCE and ECCE, age range 76-80 had the worst final visual acuity outcome $6 / 24$ and 6/18 respectively. From this study, it is concluded that there is poor prognosis of senile cataract extraction with increasing age.
\end{abstract}

KEYWORDS: Comobidity, Intracapsular, Extracapsular, Cataract, Visual Acuity.

\section{INTRODUCTION}

Cataract is the opacification of the lens. It consists of aggregation and denaturation of the lens proteins, which are normally, regularly dispersed, and which have molecules small enough relative to the wavelength of light not to interfere with its transmission ${ }^{1}$. The causes of cataract are multifactorial and complex. Some of the risk factors are age (the strongest risk factor), diabetes mellitus, sunlight, steroids, nutrition, smoking and alcohol $^{2}$.

The opacification of the lens with age normally occurs in persons above fifty years of age. It can be in the cortex-cortical cataract, nucleus-nuclear cataract or posterior subcapsular-posterior subcapsular cataract ${ }^{3}$.

On progression of cataract to such an extent that it interferes with normal daily activities of the individual, surgical removal of caracteous lens remains the only effective treatment available to restore or maintain vision. The surgical removal can be by removing the lens with its posterior capsule (intracapsular extraction) or without it (extracapsular extraction).

The goal of cataract extraction is to improve vision, relief patient of symptoms and improve visual function thereby improving quality of life ${ }^{1}$. The success of surgery has been measured in terms of visual acuity, complications following surgery; gains in visual function, health and vision related quality of life.

Best corrected visual acuity following cataract surgery is the most widely acceptable clinical indicator of surgical outcome ${ }^{4-6}$. Every patient before cataract surgery wishes to be reassured of a successful outcome. In a study carried out by Wescott et $\mathrm{al}^{7}$, on patients aged 60years and older that underwent cataract extraction, it was found that in patients with no ocular or systemic comorbidity, the ability to achieve an acuity of $6 / 12$ or better after cataract extraction were 4-6times higher in 60-69years group than in the oldest age group (80 and older).

In the broader UK population, people aged 90years and over were also four times more likely to have visual acuities worse than $6 / 12$, compared with those aged 50-59 years after the presence of ocular comorbidity was controlled for ${ }^{5}$.

Similarly, a study by Schein et $\mathrm{al}^{8}$, showed that people age 75 to 95 years were 3.6 times more likely not to improve in at least one cataract surgery outcome including self-perceived visual function, 
than people aged 50-64 years, after adjustment for ocular comorbidities and other adjustment factors. However, Lundstrom et $\mathrm{al}^{9}$, specifically looking at people aged 85 years and over, it showed that overall results were excellent, about $85 \%$ of patients had improved visual acuity and $87 \%$ perceived some benefit from the surgery.

It is estimated that eleven thousand cataract extractions are being performed annually in Nigeria $^{10}$. Among different senile age groups that undergo senile cataract extraction, are some more likely to benefit than others? Is the visual acuity outcome affected by age? The answers to these questions are important to different age groups of senile patients contemplating senile cataract surgery.

This study was aimed at answering the questions above that is, determining if age can be a factor in predicting the prognosis of the senile cataract surgery.

\section{MATERIALS AND METHOD}

Clinical records of 240 patients who had undergone cataract surgery, both intracapsular and extracapsular extractions with intraocular lens implant (IOP) within a period of 10 years (from January 1991 to December 2000) in three randomly selected hospitals were used for this study. They comprised of 119 females and 121 males within the age range of 51 to 80 years. The patients included in the study did not have any ocular disease and systemic disease like hypertension, diabetes, bronchitis, asthma, bleeding and coagulation disorders.

Data abstraction forms were used to record the necessary data collected from the clinical records of the patients. The data abstraction form included age, sex, entry VA, pupillary reaction, light projection and perception, external examination finding, ocular problems prior to surgery, type of extraction, VA after extraction, VA after final refraction and complications.

The 240 patients' records were grouped according to the type of cataract extraction done. 157 patients comprising 75 females and 82 males underwent ICCE with IOL, 83 patients comprising 44 females and 39 males underwent ECCE with IOL. The patients were further grouped into six difference age ranges $(51-55,65-60,61-65,66-70$, $71-75,76-80)$ years. Simple one way analysis of variance (ANOVA), correlation and regression analysis were used to statistically analyze results.

\section{RESULTS}

The total sample size was 240 for both ECCE and ICCE with age range 51-80. For ICCE, the sample size was 157 (65.42\%), while for ECCE, 83 $(34.58 \%)$. The sample population was divided into six age groups for the total population, ICCE and ECCE each.

In other to calculate the mean VA for each age group, the VA was converted to decimal. Table1 shows the mean VA of different age groups and their frequency distribution. From the table, age group 51-55 had best mean VA of 6/9. Age group 76-80 had the worst VA with mean VA of 6/24.

Table 2 shows the mean VA of different age groups in ICCE and their frequency distribution. From the table, age group 61-65 with mean VA of 6/9 had the best VA and age group 76-80 with mean VA 6/24. Table 3 shows the mean VA and frequency of different age groups in ECCE. From this table, age group 51-55 with mean VA of 6/7.5 had the best VA while age group 76-80 had the worst mean VA of $6 / 18$.

Fig. 1 shows a regression line of VA and age for ICCE population. This means that there was reduction in VA after cataract extraction as age increased. Fig. 2 shows a regression of VA and age for ECCE population. This means that there was reduction in VA after cataract extraction as age increased. Fig. 3 shows a regression line of VA and age for the total population. This means that there was reduction in VA after cataract extraction as age increased.

\section{DISCUSSION}

In this study involving 240 patients between 51-80 years of age who underwent cataract extraction, table 1 shows the mean VA of different age groups in the total population. Age group 51-55 had the best mean VA of 6/9, while age group of 7680 had the worst mean VA of 6/24. This is consistent with the result obtained by Schein el al ${ }^{8}$ which indicates that people aged 75 to 95years were 3.6 times more likely not to improve in at least one cataract surgery outcome including visual acuity, self perceived visual function, than people aged 50-64 years after adjustment for ocular comorbidities and other facts. 
Furthermore, table 2 showed the mean VA of different age groups in ICCE, indicated that age group 61-65 had the best VA of 6/9 while the age group of 76-80 had the worst mean VA of 6/24. In table 3, which showed the mean VA of different age group in ECCE, age group 51-55 had the best mean VA of 6/7.5 while age group of 76-80 had the worst mean VA of $6 / 18$. The findings above are in accordance with the result obtained by Desai et $\mathrm{al}^{5}$, which demonstrated that people aged 90 years and over were four times more likely to have visual acuity worse than $6 / 12$ compared with those aged 50-59 though phacoemulsification was the surgical technique used. Table 1, 2 and 3 showed that age group 76-80 had the worst mean VA (that is in ICCE, ECCE and total population) and age group 51-55, 61-65 and 51-55 had the best mean VA in total population ICCE and ECCE respectively.

The results of this study showed that the younger age group achieved a better visual acuity, while the oldest age group in this study achieved the worst visual acuity. The decreased acuity found in the oldest age group in the two techniques is probably due to a combination of changes within the aging eye, including cell loss in the fovea, decreased transparency of the vitreous and increased light scatter and glare within the tissues of the eye ${ }^{11}$. Fig. 1 which is the linear regression graph of VA and age, demonstrated that as age increases, the final visual acuity outcome after intracapsular cataract surgery decreases. Also, fig. 2 , displayed a negative correlation between age and final visual acuity outcome. This also implies that as age increases, the final visual acuity outcome after ECCE decreases. This is consistent with the findings of Wescot et $\mathrm{al}^{7}$.

Fig. 3 which is the graph of regression of VA and age for the total population displayed a negative correlation between age and final visual acuity outcome after cataract extraction. This implies that as age increases the visual acuity outcome decreases. In all, the results showed that a strong relationship exist between age and final visual acuity outcome after ICCE and ECCE. As age increases, the visual acuity outcome after extracapsulsr and intracapsular cataract extraction decreases.

The decrease in visual acuity with increasing age after both ICCE and ECCE may be related to ocular anatomical and neural changes that accompany aging. These includes $\ddot{i}$ thickening of the cornea with aging which adds to the amount of extra light scatter already inside the aging eye, the decrease in pupil diameter with aging which reduces the amount of light that the older adult receives, increase in posterior vitreous detachment as one ages which causes blurred and distorted images and flashes of light, increased glare with aging resulting from loss of retinal cells, loss of neurons (which are irreplaceable) due to age in the visual pathway and decreased reaction time to stimuli by neurons with age. The combination and independent effect of these anatomical and neural changes result in decreased visual acuity with increasing age $\mathrm{e}^{12-14}$.

The result of this research work has shown that a strong relationship exist between age and final visual acuity outcome after both ICCE and ECCE. From this study, it can be concluded that age is a significant determinant of the final visual acuity outcome after senile cataract extraction. Therefore, in senile cataract patients between the ages of 51 and 80 years, equal visual acuity should not be expected after cataract extraction.

\section{TABLE 1: MEAN VAAGE IN TOTAL SAMPLE POPULATION}

\begin{tabular}{|lll|l|}
\hline Age group & N & \% (frequency) & Mea VA \\
\hline 51 ï 55 & 56 & 23.33 & $6 / 9$ \\
\hline 56 ï 60 & 32 & 13.33 & $6 / 12$ \\
\hline 61 ï 65 & 50 & 20.83 & $6 / 12$ \\
\hline 66 ï 70 & 47 & 19.58 & $6 / 18$ \\
\hline 71 ï 75 & 34 & 14.17 & $6 / 18$ \\
76 ï 80 & 21 & 8.75 & $6 / 24$ \\
\hline Total & 240 & 100 & \\
\hline
\end{tabular}


TABLE 2: MEAN VA WITH AGE GROUPS IN ICCE POPULATION

\begin{tabular}{|lll|l|}
\hline Age group & N & \%(frequency) & Mean VA \\
\hline 51 ï 55 & 43 & 27.39 & $6 / 12$ \\
\hline 56 ï 60 & 23 & 14.65 & $6 / 12$ \\
\hline 61 ï 65 & 29 & 18.47 & $6 / 9$ \\
\hline 66 ï 70 & 28 & 17.83 & $6 / 12$ \\
\hline 71 ï 75 & 19 & 12.10 & $6 / 18$ \\
76 ï 80 & 15 & 9.55 & $6 / 24$ \\
\hline Total 6 & 157 & 100 & \\
\hline
\end{tabular}

TABLE 3: MEAN VA WITH AGE IN ECCE POPULATION

\begin{tabular}{|lll|l|}
\hline Age group & $\mathbf{N}$ & \%(frequency) & Mean \\
\hline 51 ï 55 & 15 & 15.66 & $6 / 7.5$ \\
\hline 56 ï 60 & 9 & 10.84 & $6 / 9$ \\
\hline 61 ï 65 & 21 & 25.30 & $6 / 9$ \\
\hline 66 ï 70 & 19 & 22.89 & $6 / 12$ \\
\hline 71 ï 75 & 15 & 18.09 & $6 / 12$ \\
76 ï 80 & 6 & 7.23 & $6 / 18$ \\
\hline Total & 83 & 100 & \\
\hline
\end{tabular}

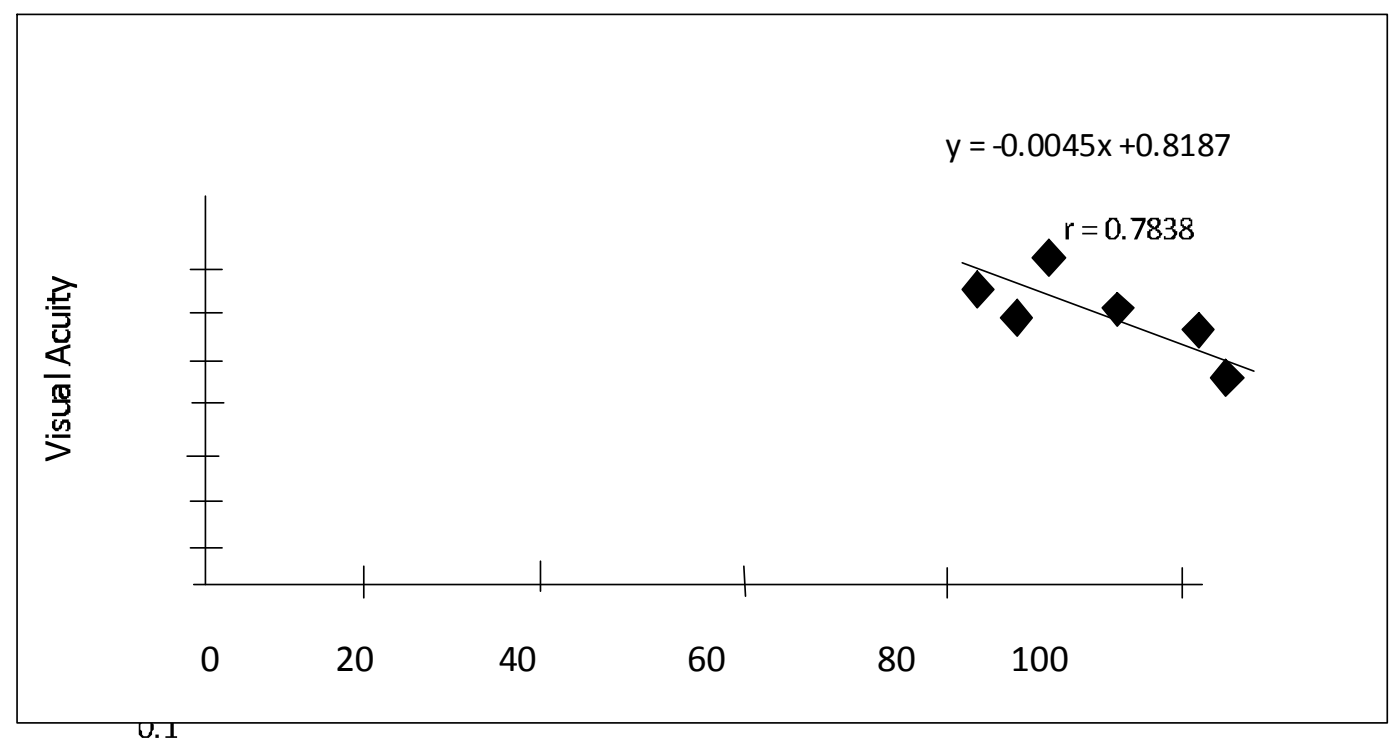

FIG. 1: REGRESSION OF VA LINE AND AGE FOR ICCE 


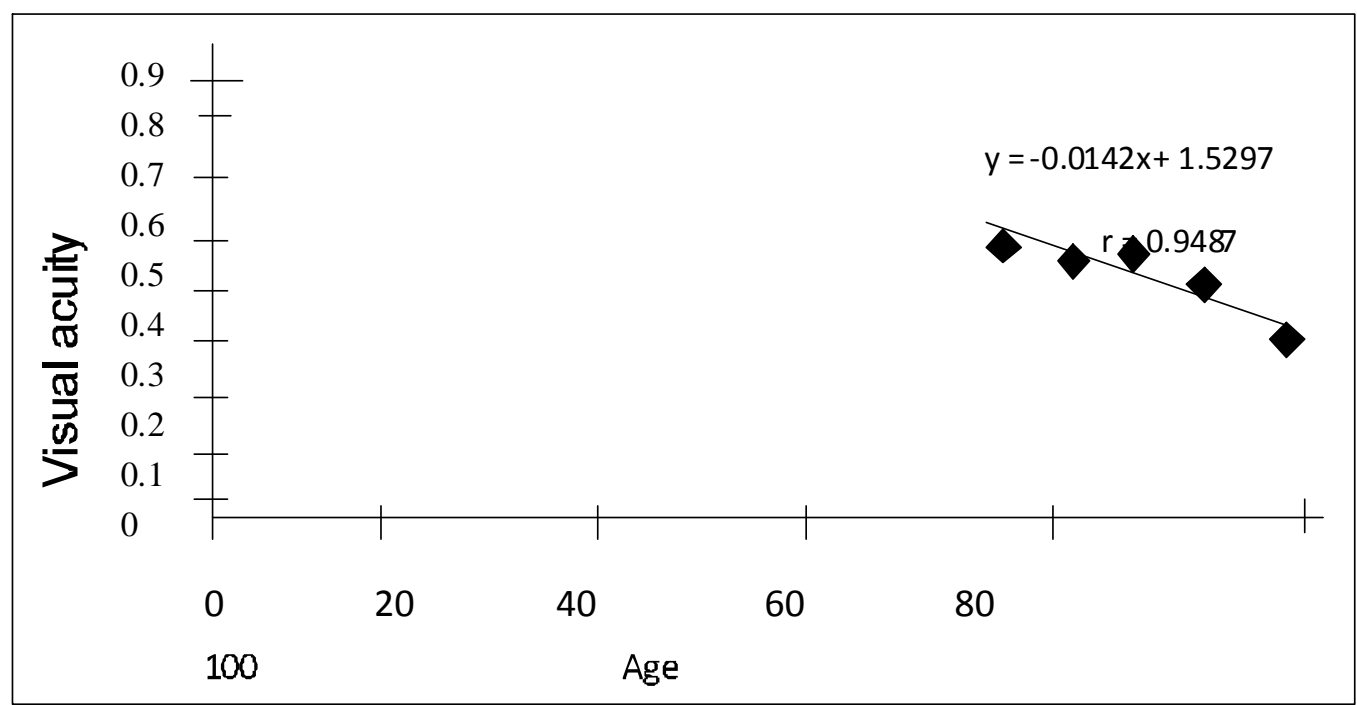

FIG. 2: REGRESSION OF VA LINE AND AGE FOR ECCE

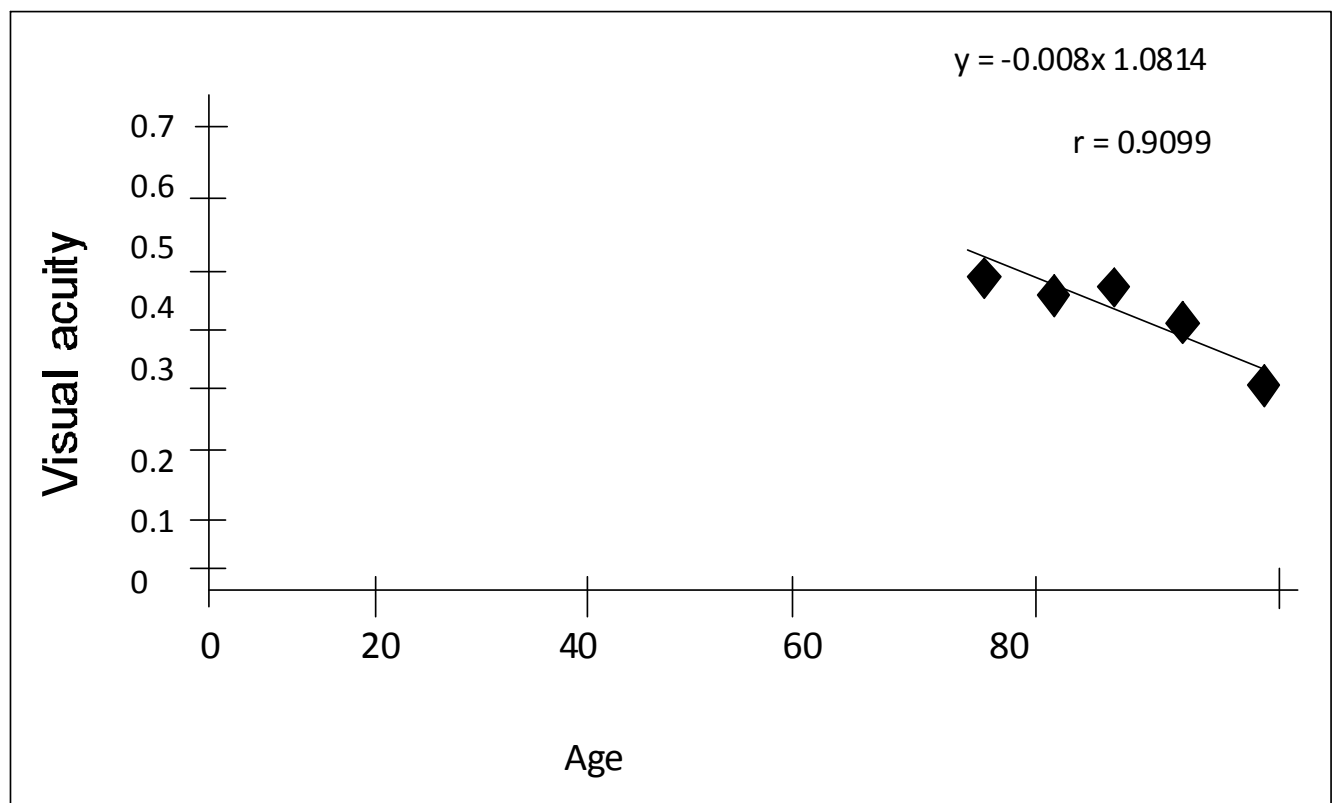

FIG. 3: REGRESSION OF VA LINE AND AGE FOR THE TOTAL POPULATION 


\section{RE F E R E N C E S}

1. Cassin, B. (1998): Eye disorders. Fundamentals for Ophthalmic Technical Personnel. $1^{\text {st }}$ Edn. W. B. Saunders Company, Pennysylvia, 8:103-19.

2. Dollin, P. (1998): Epidemiology of cataract. The Epidemiology of the eye disease. $1^{\text {st }}$ Edn. Chapman and Hall Medical, London, 20: 1039.

3. Kanski, J. J. (1996): Disorders of the Lens. Clinical Ophthalmology. $3^{\text {rd }}$ Edn. Butterw orthHeinemann, Oxford, 286pp.

4. Desai, P. (1993): National Cataract surgery. Survey II: Clinical outcomes. Eye, 7: 489-94.

5. Desai, P., Minassian, D. C., and Reidy, A. A. (1999): Report of the results of the clinical outcomes. Br. J. Ophthalmol, 83:1336-40.

6. Desai, P. Reidy, A., Minassian, D. C., Vafidis, G., and Bolger, J. (1996): Visual Function and quality of life. Br. J. Ophthalmol, 80:868-73.

7. Wescortt, M. C., Tuft, S. J. and Minassian D. C. (2002): Effect of age on Visual outcome following cataract extraction. Br. J. Ophthatlmol, 84:1380-3.

8. Schein, O. D., Steinberg, E. P., Cassard, S. D., Tielsch, J. M., Javitt J. C. and Sommer, A.
(1995): Predictors of outcome in patients who underwent cataract Surgery. Ophthalmol, 102: 817-23.

9. Lundstrom, M., Stenevi, U. and Thorburn, W. (2000): Cataract surgery in very elderly. J. Cataract Refract. Surg, 24:408 -14.

10. Foster, A. (2000): Vision 2020: The Cataract Challenge. J. Comm. Eye Hlth, 13:17-9.

11. Haeger Strom-Portnoy, G. (1999): Seeing into old age. Optom. Vis. Sci, 76:141-58.

12. Oberlink, M. (1997): Keeping an eye on vision. Primary care of age-related ocular disease. Geriatrics, 52:30-7.

13. Ordy, J. M., Brizzee, K. R. and Johnson H. A. (1982): Cellular alterations in visual pathways and the Limbic system: Implication for vision and short term memory. In R. Sekuler D. Kline, and K. Dismukes (Edn.), Aging and Human Visual function. Alan R. Liss Inc, New York pp79- 114.

14. Balazs, E. A. and Delinger, J. L. (1982): Aging changes in the vitreous. In R. Sekuler, D. Kline and K. Dismukes (Edn), Aging and human visual function. Alan R. Liss. Inc, New York,pp 45-57. 